
\section{International Scientific Journal Theoretical \& Applied Science}

\author{
p-ISSN: 2308-4944 (print) e-ISSN: 2409-0085 (online) \\ Year: $2015 \quad$ Issue: $03 \quad$ Volume: 23 \\ Published: $30.03 .2015 \quad \underline{\text { http://T-Science.org }}$
}

Section 19. Management. Marketing. Public administration.
Tatiana Vitalievna Butova

Deputy Dean of the faculty of Public and municipal administration, Candidate of Economic Science, Docent,

Financial University under the Government of the

Russian Federation, Russia tvbutova@mail.ru

Eduard Ruslanovich Tambiev

the second-year student of Public and Municipal Administration faculty, Financial University under the Government of the Russian Federation, Russia

Andrei Jurievich Chikin the second-year student of Public and Municipal Administration faculty,

Financial University under the Government of the Russian Federation, Russia chikin95@list.ru

\title{
THE WAYS OF IMPROVEMENT OF LOCAL GOVERNMENT IN THE ALSHEEVSKY DISTRICT
}

Abstract: In the work the question of effectiveness increase of self-government in the Alsheevsky district of the Republic of Bashkortostan is considered. The authors touch upon the ways and directions of development of this policy for 2015-2016 on basis of the characteristic of budgetary and tax policy of this municipal area.

Key words: municipal administration, budgetary policy, municipal entity, tax policy, taxation, revenue base, expenses.

Language: Russian

Citation: Butova TV, Tambiev ER, Chikin AJ (2015) THE WAYS OF IMPROVEMENT OF LOCAL GOVERNMENT IN THE ALSHEEVSKY DISTRICT. ISJ Theoretical \& Applied Science 03 (23): 122-125.

Soi: http://s-o-i.org/1.1/TAS*03(23)22 Doi: crossef http://dx.doi.org/10.15863/TAS.2015.03.23.22

\section{ПУТИ СОВЕРШЕНСТВОВАНИЯ МЕСТНОГО САМОУПРАВЛЕНИЯ В АЛЬШЕЕВСКОМ РАЙОНЕ}

Аннотация: В работе рассматривается вопрос повышения эффективности самоуправления 6 Альшеевском районе Республики Башкортостан. На основе характеристики бюджетной и налоговой политики указанного муниципального района авторы приводят пути и направления развития данных политик на 2015-2016 годы.

Ключевые слова: муниципальное управление, бюджетная политика, муниципалитет, налоговая политика, налогообложение, доходная база, расходы.

Рассмотрим совершенствования Альшеевском районе.

Первое направление - совершенствование экономических механизмов муниципального управления. Данное направление включает в себя целый ряд задач. На сегодняшний момент совершенствование экономического механизма муниципального управления основывается, в первую очередь, в оптимизации налоговой и бюджетной политики.

Эволюция налогового и бюджетного законодательства в последнее десятилетие ограничивало финансовую автономию и обеспеченность муниципальных образований. В связи с сокращением перечня налоговых источников местных бюджетов практически все муниципальные образования стали дотационными - даже среди наиболее обеспеченных городских округов таковых более $92 \%$. В структуре финансовой помощи местным бюджетам все большее значение приобретают те дотации, направления расходования которых определяются самими муниципалитетами, и субсидии, т.е. долевое участие вышестоящего уровня бюджетной системы в расходах, которые субъект Федерации считает необходимыми.

По этой причине муниципальные образования пока не смогли активно приступить к работе по оптимизации своих расходов выделению эффективных и неэффективных трат и отказу от финансирования последних, что 
являлось одной из задач бюджетного реформирования. Обязательными предпосылками для таких изменений являются известная самостоятельность муниципалитетов в определении бюджетных расходов и наличие стимулов в развитии своей доходной базы. Следующее направление совершенствования экономических механизмов муниципального управления состоит в достижении финансовой самодостаточности муниципального управления [10, c. 77].

Стратегическим ориентиром здесь должно стать замещение в бюджетах муниципальных образований с относительно высоким уровнем социально-экономического развития финансовой помощи федерального и регионального бюджетов поступлениями от собственных доходных источников. Необходимо исключить бессмысленное циркулирование средств от муниципального образования в бюджеты вышестоящих уровней бюджетной системы с последующим возвращением их в тот же муниципалитет в качестве межбюджетных трансфертов. Следует рассмотреть вопрос о закреплении за местными бюджетами на долгосрочной основе дополнительных налоговых источников, стимулирующих муниципалитеты к работе над собственной доходной базой, что позволит в перспективе расширить налогооблагаемую базу не только для местных, но также для федерального и региональных бюджетов [4, с. 99].

Бюджетная и налоговая политика муниципального района Альшеевский район Республики Башкортостан на период 2015 и 2016 годов должна продолжить курс, выстроенный на принципах ответственности и предсказуемости модели управления финансами в целях сохранения социальной и финансовой стабильности в районе.

Приоритетными направлениями бюджетной и налоговой политики муниципального района на 2015-2016 годы должны являться:

- обеспечение финансовой устойчивости и стабильности бюджетов всех уровней, в связи с этим бюджетное планирование будет базироваться на умеренно оптимистичных оценках макроэкономического прогноза; развитие доходного потенциала муниципального района и ее муниципальных образований на основе формирования стабильной и эффективной налоговой системы;

- увязка основных подходов к структурным реформам с объективными бюджетными ограничениями;

- сдерживание роста расходных обязательств муниципального района по публичным нормативным обязательствам путем проведения анализа установленных социальных гарантий, размеров выплат, количества получателей и оптимизации мер социальной поддержки населения по всем основным социальнодемографическим группам с учетом нуждаемости получателей;

- проведение эффективной и рациональной инвестиционной бюджетной политики;

- модернизация социальной, инженерной и дорожной инфраструктуры;

- оказание государственной поддержки отдельным категориям граждан в целях повышения доступности и уровня обеспеченности населения района жильем;

- организация предоставления и финансовое обеспечение муниципальных услуг с установлением и соблюдением требований по их качеству и результативности на основе муниципального задания и принципов нормативного финансирования;

- продолжение поэтапного внедрения программно-целевого принципа организации деятельности органов исполнительной власти, своевременная разработка и повышение качества принимаемых целевых программ для формирования программного бюджета,

- переход к утверждению и исполнению закона о бюджете муниципального района в трехлетнем формате;

- создание стимулов для улучшения качества управления муниципальными финансами;

$$
\text { обеспечение качественного }
$$
прогнозирования кассовых поступлений в бюджет и кассовых выплат из бюджета участниками бюджетного процесса;

развитие механизмов кассового обслуживания получателей бюджетных средств, бюджетных и автономных учреждений, в том числе проведение кассовых операций со средствами бюджетных и автономных учреждений муниципального района в соответствии с объемами доведенного учредителем муниципального задания, составленного с учетом необходимости предоставления конкретной муниципальной услуги (работы), соответствующей стандартам качества ее предоставления;

- дальнейшее снижение наличного денежного обращения путем обеспечения преимущественно безналичного денежного оборота при проведении бюджетных платежей;

- разработка и внедрение стандартов финансового контроля;

- усиление мер по привлечению к ответственности за финансовые нарушения должностных лиц; 
- обеспечение прозрачности и открытости бюджетного процесса, развитие информационной системы управления муниципальными финансами [9, с. 14].

В основу налоговой политики муниципального района на 2015 и 2016 годов должны быть положены стратегические ориентиры, определенные Основными направлениями налоговой политики Российской Федерации. Ключевой задачей налоговой политики должно стать развитие доходного потенциала муниципального района и ее муниципальных образований с целью обеспечения сбалансированности бюджетов всех уровней. Для решения данной задачи необходимо продолжение практики применения стимулирующих механизмов, созданных в муниципальном районе с целью улучшения налогового климата для инвесторов, предпринимателей и повышения конкурентоспособности приоритетных видов деятельности экономики, а также совершенствование действующего законодательства и усиление взаимодействия контролирующих и правоохранительных органов власти по ликвидации имеющихся возможностей для уклонения от налогообложения [2, с. 64].

Совершенствование механизма налогового стимулирования субъектов малого и среднего предпринимательства подразумевает:

- реализацию положений главы «Патентная система налогообложения» Налогового кодекса Российской Федерации;

- реализацию положений Закона Республики Башкортостан «О патентной системе налогообложения в Республике Башкортостан» $[6$, c. 8].

С целью решения задачи по диверсификации экономики необходимо обеспечить сохранение неизменности налоговой нагрузки по секторам экономики, в которых достигнут ее оптимальный уровень. В этой связи принятие решений по вопросам налоговых льгот в виде снижения налоговой ставки отдельным категориям налогоплательщиков планируется на основе анализа практики применения, их эффективности.

Росту самодостаточности муниципальных образований за счет повышения собственных доходов местных бюджетов будут способствовать следующие меры:

- проведение работы по мобилизации доходов и повышение качества администрирования налоговых и неналоговых доходов муниципальных образований;

- совершенствование стимулирующего механизма роста доходов местныхбюджетов;

- закрепление на федеральном уровне за бюджетами муниципальных образований 100 процентов доходов в виде единого сельскохозяйственного налога, поступлений от патентной системы налогообложения;

- установление единого норматива отчисления налога, взимаемого в связис применением упрощенной системы налогообложения, в бюджет муниципального района (в размере 100 процентов) [7, с. 125].

Бюджетная политика в области расходов на 2015-2016 годы должна быт направлена на повышение эффективности бюджетных расходов путем внедрения в деятельность органов муниципальной власти муниципального района Альшеевский район Республики Башкортостан и муниципальных учреждений программно-целевых методов управления.

\section{References:}

1. (2014) Gradostroitelnyiy Kodeks ot 24.11.2014 \# 190-FZ / Spravochno-pravovaya sistema «Konsultant Plyus»: [Elektronnyiy resurs] / Kompaniya «Konsultant Plyus».

2. Bossel H (2001) Pokazateli ustoychivogo razvitiya: Teoriya, metod, prakticheskoe ispolzovanie. Otchet, predstavlennyiy na rassmotrenie Balatonskoy gruppyi / Per. s angl. - Tyumen: Izd-vo IPOS SO RAN, 2001. - 123p.

3. Granberg AG (2004) Osnovyi regionalnoy ekonomiki: uchebnik. - 4-e izd. - M.: GU VShE, 2004. - 495 p.
4. Neznamova EA (2012) K voprosu o nekotoryih novyih polozheniyah zakonodatelstva o mestnom samoupravlenii. / Gosudarstvennaya vlast i mestnoe samoupravlenie. - 2012. - \# 5. pp.7 - 11

5. Polyakova AG (2013) Obespechenie ustoychivogo razvitiya munitsipalnogo obrazovaniya $\mathrm{v}$ protsesse evolyutsii: dis. kand. ekon. nauk: 08.00.05: Tyumen, 2013. - 168 p.

6. Ragulina YV (2014) Maloe predprinimatel'stvo kak sub"ekt ehkonomicheskogo razvitiya / 
EHkonomika i predprinimatel'stvo. 2014. № 5. pp. 633.

7. Ragulina YV, Zvanbaya SO, Chekmeneva TN, Sudib'e AO (2014) Vzaimodejstvie vlasti i biznesa $\mathrm{V}$ reshenii problem municipal'nyh obrazovanij / Municipal'naya akademiya. 2014. № 1. pp. 28-34.

8. Suvorov GN (2013) Statya: Sistematizatsiya istochnikov rossiyskogo konstitutsionnogo prava
/ Gosudarstvennaya vlast i mestnoe samoupravlenie. - 2013. - \# 3. - pp. 17-19

9. Tihomirov YA (2011) Pravovoe gosudarstvo: modeli i realnost / Zhurnal rossiyskogo prava. 2011. - \#12. - pp. 5-20.

10. Chertkov AN (2011) Sub'ekt federatsii kak gosudarstvenno-territorialnaya edinitsa / Zhurnal rossiyskogo prava. - 2011. - \#1. - pp.76-81. 